\title{
Educação Patrimonial e Políticas de Escolarização no Brasil
}

\author{
Rodrigo Manoel Dias da Silva' \\ 'Universidade do Vale do Rio dos Sinos (UNISINOS), São Leopoldo/RS - Brasil \\ RESUMO - Educação Patrimonial e Políticas de Escolarização no Brasil. \\ $\mathrm{O}$ artigo visa reconstruir a trajetória da educação patrimonial nas políticas \\ brasileiras de escolarização a fim de compreender os deslocamentos em \\ seus conteúdos político-culturais, de um modelo de educação centrado na \\ formulação ideológica de uma unidade nacional para um estatuto erigido \\ sob a égide da diversidade cultural. A partir de análise documental, con- \\ clui que os sentidos atribuídos à educação patrimonial acompanham uma \\ tendência à patrimonialização das diferenças, mediante o reconhecimento \\ de atores e grupos sociais não incorporados às políticas. Contudo, sua pre- \\ sença nesse contexto ainda é bastante periférica, tendo em vista os diversos \\ interesses socioeconômicos em disputa na definição de patrimônio e em \\ suas práticas. \\ Palavras-chave: Cidadania. Escolarização. Educação Patrimonial. Diver- \\ sidade Cultural.
}

ABSTRACT - Cultural Heritage Education and Brazilian Schooling Policies. This paper aims to reconstruct the trajectory of cultural heritage education in Brazilian schooling policies in order to understand the shifts in their political and cultural contents, from a model of education centered on the ideological formulation of a national drive to a statute erected under the aegis of cultural diversity. Based on document analysis, it concludes that the meanings assigned to cultural heritage education follow a tendency to the patrimonialization of differences through the recognition of actors and social groups not incorporated into the policies. However, its presence in this context still is quite peripheral, given the number of different socioeconomic interests in dispute in the definition of heritage and in their practices. Keywords: Citizenship. Schooling. Cultural Heritage Education. Cultural Diversity.

Educação \& Realidade, Porto Alegre, v. 41, n. 2, p. 467-489, abr./jun. 2016. 467 http://dx.doi.org/10.1590/2175-623655022 


\section{Apresentação}

É possível reconhecer as relações entre escolarização e processos de patrimonialização cultural em diversos momentos da história da educação brasileira, igualmente nas próprias narrativas de efetuação da escolarização massiva no Brasil e na América Latina (Tiramonti, 2005; Schwartzman; Bonemy; Costa, 2000), ou mesmo na instituição das lógicas que engendraram as políticas para o patrimônio cultural, histórico ou artístico (Delgado, 2008; Calabre, 2009). A educação patrimonial, em seus estágios germinais, esteve na pauta na produção da modernidade, da cidadania e da educação pública no Brasil. Circunscrita por interesses políticos diversos, por objetivações econômicas ou materiais, por constructos ideológicos plasmados ao imaginário nacional ou por lógicas de pertencimento a uma comunidade imaginada (Anderson, 2008), é possível vislumbrarmos indícios de sua emergência.

Hoje, porém, novas produções discursivas, dinâmicas sociais e relações de poder passam a estabelecer parâmetros diferenciados para as formas jurídicas que organizam as políticas, igualmente ressignificando os conteúdos e as práticas que lhe constituem. Nesta paisagem, temáticas como diversidade cultural, reconhecimento, pluralidade e diferença passam a compor novos vocabulários institucionais e vão modificando dispositivos e pressupostos normativos presentes nos delineamentos de tais políticas. Essa emergência, particularmente quanto ao termo diversidade cultural, é derivada de um conjunto de iniciativas, lutas e mobilizações de atores e movimentos sociais pela garantia da democratização sociocultural, com ênfase em sociedades que experimentaram longos períodos de cerceamento militar. Em escalas mais amplas, três processos sociais aprofundaram o advento da diversidade cultural como categoria amplamente utilizada para interpretar o tempo presente. A globalização da economia, primeiramente, alterou os mecanismos de integração e articulação dos atores sociais, mediante políticas e direitos internacionais que padronizaram os procedimentos de relação com as culturas. A modernização dos Estados, a seguir, corroborou para a produção de um campo conflitivo de lutas entre a diversidade e suas relações de força, desencadeando, por vezes, a transferência das reivindicações sociais dos direitos coletivos para as estruturas estatais, mediante ajustes burocráticos, e as constantes intersecções com agências internacionais como a Unesco ou o Banco Mundial. E, ainda, a democratização, conceito este que, por sua amplitude, procurou garantir a legitimidade oficial do reconhecimento da diversidade cultural, mas tornou-se insuficiente para estabelecer novas relações de poder e fomentar padrões de justiça social e enfrentamento das desigualdades sociais (Zambrano, 2000).

O presente artigo visa a reconstruir a trajetória da educação patrimonial nas políticas de escolarização no Brasil, a partir de análise teórica, a fim de compreender a ocorrência de deslocamentos no plano 
de seus conteúdos político-culturais, sinteticamente visibilizados na transição de um modelo moderno (clássico) de educação centrado na formulação ideológica de uma unidade nacional para um novo estatuto erigido sob a égide da diversidade cultural.

Para enfrentarmos esta problematização, organizamos o presente artigo em três seções textuais. Na primeira seção, nosso objetivo consiste em produzir uma contextualização sociológica sobre as relações entre educação, cidadania e cultura nacional diante do surgimento da ordem social moderna. Na segunda, analisaremos a produção histórica da escolarização no Brasil, interessados em demonstrar que unidade nacional e homogeneidade cultural compuseram uma agenda civilizatória aos programas de massificação escolar e, consequentemente, produziram sentidos às relações entre educação e patrimônio cultural. Na terceira, analisaremos os sentidos contemporâneos atribuídos à educação patrimonial, a partir da inserção da temática na agenda político-educativa do país (Brasil, 2009; 2012), mediante estudo documental.

\section{Educação, Cidadania e Cultura Nacional: leituras da modernidade}

Embora os termos moderno e modernidade possuam uma longa história no estudo das sociedades, a Modernidade, tal como tratada pela Sociologia, é derivada das mudanças sociais consequentes da Revolução Industrial, da Revolução Francesa e da Revolução Científica. Em termos genéricos, refere-se "à ordem social que emergiu depois do Iluminismo” (Lyon, 1998, p. 35).

Diversas tradições teóricas destacadas no pensamento sociológico abordaram estes fenômenos, sobretudo àquelas originadas da produção de Marx, Weber, Durkheim e Simmel. As sociedades modernas tornaram-se o objeto strictu da Sociologia (Giddens, 1991; Lyon, 1998; Domingues, 2003). Assim, diversas têm sido as caracterizações e as análises dos fenômenos modernos e da ordem social instituída, ora acentuando perspectivas analíticas unidimensionais, ora atentas à multidimensionalidade dos processos socioculturais em vigor (Giddens, 1991). Nosso interesse aqui reside em contextualizar histórica e sociologicamente as relações entre cidadania e educação escolar na ordem social moderna. Tal contexto permite-nos descrever os movimentos sociopolíticos e pedagógicos que potencializaram a recuperação do conceito de patrimônio cultural, ou seja, sua posição ${ }^{1}$ (Martín-Barbero, 2009) nas políticas do Estado Nacional moderno e evidencia-nos algumas de suas ressonâncias contemporâneas.

Segundo Dubet (2011, p. 289), a instituição escolar republicana na França foi idealizada como a escola da cidadania, numa situação onde a invenção de uma escola laica, pública, gratuita e obrigatória erigiu enquanto oposição à influência da Igreja Católica sobre os processos formativos de crianças e jovens. Embora razão, ciência, progresso e nação 
compusessem as bases ideológicas da escola republicana, não significou que esta fosse antirreligiosa; seus pressupostos morais e de controle das condutas mantiveram-se tal como no período histórico antecedente. Essa escola pretendia manter a sacralidade da Igreja, a partir de uma moral comum e uma liberdade individual, transferindo o objetivo de formar fieis para formar cidadãos. Esse processo, de algum modo, foi descrito por Norbert Elias (2011), quando este afirma que o processo civilizador moderno correspondeu ao controle ou abrandamento interno das pulsões humanas. O indivíduo precisaria passar por um processo formativo sistemático e duradouro para civilizar-se, assim como, escolarizando-se, tornar-se-ia cidadão.

Se o conceito de cidadania primeiramente surge entre os séculos V e IV a.C. (Manzini, 2010; Gohn, 2008), desde o Iluminismo tal conceito assume novos contornos. Embora polissêmico, o termo traz em si as marcas de uma civilização ocidentalizada e associada a uma cultura de direitos individuais (Marshall, 1967). Ao perscrutar o conceito, François Dubet identificou três elementos constituintes da ideia moderna de cidadania, os quais irão balizar a sequência desta seção.

$\mathrm{O}$ primeiro elemento diz respeito à produção coletiva ou (convencionalmente) social da cidadania, o qual foi nomeado $O$ cidadão de uma nação (Dubet, 2011). Neste, o sociólogo menciona a dimensão de pertencimento do cidadão a uma determinada comunidade, grupo ou nação, o qual demarca os limites ou as fronteiras da cidadania. Nos termos do autor,

\begin{abstract}
Mas, em todos os casos, quer a cidadania fosse mais ou menos ampla, ela foi primeiramente considerada a expressão de uma nação. De uma nação de cidadãos evidentemente, mas de uma nação definida por suas especificidades, sua língua, sua cultura, sua história e, sobretudo, por sua vontade de ser nação. Nesse sentido, a cidadania repousa sobre uma relação de fidelidade à nação - é-se cidadão de Veneza ou cidadão de Florença, cidadão da França ou dos Estados Unidos - e não mais sobre uma fidelidade direta e pessoal ao suserano como na sociedade feudal (Dubet, 2011, p. 290).
\end{abstract}

Embora pertinente à realidade francesa, este modelo expandiu-se pelo Ocidente, inclusive aos Estados derivados dos movimentos de libertação nacional desencadeados no século XX. A ideologia de produção de uma unidade nacional, a partir de um patrimônio e uma memória comum, foi balizadora da cidadania moderna, a qual foi fabricada a partir da escolarização massiva. A unidade territorial, linguística e cultural estava nos meandros da escola republicana.

A escola republicana ensina a história e a geografia da nação. Essa história mostra que a França é fruto de uma longa gestação para a qual todos os reis, todos os heróis, todos os grandes homens contribuíram pondo a sua pe- 
dra. Na escola, a história é, sobretudo, um relato do qual as crianças devem sentir-se as herdeiras. A geografia preenche a mesma função. [...] As grandes obras da cultura também participam dessa consciência nacional; todas as crianças aprendem de cor os mesmos poemas de nossos grandes escritores: La Fontaine, Lamartine, Victor Hugo... Cada um deve compartilhar uma parte do panteão cultural nacional (Dubet, 2011, p. 291).

Estava em curso todo um projeto de formação da consciência nacional, centrado na "substituição de um mosaico de comunidades locais pelo novo e estreitamente integrado sistema do Estado-nação" (Bauman, 2003, p. 114). Como observa Lílian do Valle (2000, p. 17), "a partir, sobretudo, da Revolução Francesa, o cidadão é confundido com o membro de uma nação - unidade espiritual, cultural e histórica - titular de direitos específicos". A definição da cidadania e do ser cidadão passaria a estar atrelada a critérios identitários da nação e, estes, aos fundamentais objetivos de construção da unidade e da soberania nacional (Valle, 2000).

Guillermina Tiramonti, por sua vez, menciona que tais procedimentos ocorreram também no Brasil e na Argentina, mas de outra maneira. No Brasil, densos contingentes populacionais ficaram fora do alcance das ações estatais, constituindo uma sociedade dual em que o crescimento econômico não foi capaz de neutralizar as desigualdades sociais. No país vizinho, construiu-se um modelo de integração e articulação do conjunto da sociedade a partir de fortes processos de homogeneização cultural organizados pelo Estado, sobretudo pela escolarização pública (Tiramonti, 2005).

O segundo elemento citado pelo sociólogo francês (Dubet, 2011, p. 291) se refere à produção de um "sujeito autônomo". Considera que:

O cidadão não é apenas o membro de uma nação, ele é também um sujeito autônomo, capaz de julgar por si seus interesses e os da nação. Qualquer que seja o grau de democracia, o cidadão deve colocar-se do ponto de vista do bem público, deve resistir às forças da opinião e dos demagogos, em suma, ele deve ser um virtuoso, como dizia Montesquieu.

No seio das escolas republicanas, essa virtude cidadã era ensinada de diversos modos. Tal formação virtuosa do cidadão era pautada pela laicidade e por um conjunto de valores positivos, isto é, todo ato educativo estava imbuído de propósitos moralizadores, civilizatórios e de elevação cultural (Elias, 2011). Assim contextualizada, toda educação faz-se moral, produzida socialmente e centrada na razão enquanto virtude universal, tal como descrito por Durkheim (2007). Ou, ainda, segundo Bauman (2003, p. 114-115), a construção desta nova ordem social requeria não só administradores, mas também professores, para garantir uma cultura comum de engajamento direto de governantes e governados. 
O terceiro elemento diz respeito à competência cidadã (Dubet, 2011). A formação do cidadão não é um processo natural, pois depende do aprendizado de certas competências que favoreçam suas intervenções na vida democrática, como as capacidades de escutar, de ser ouvido, de defender os seus interesses e os da coletividade, supondo que o aluno aprenderia a exercer seus direitos na prática. Embora a escola em questão não pudesse ser considerada democrática, "a aprendizagem das competências cidadãs ocorreu, portanto, por meio de alguns cursos de instrução cívica que explicavam aos alunos alguns elementos do sistema constitucional da República” (Dubet, 2011, p. 292). Neste aspecto, a cidadania moderna, pela escolarização, instaurou um paradoxo fundamental, a saber:

Ela formou os membros de uma nação, ela instalou um forte sentimento de fidelidade à laicidade opondo o universal aos pertencimentos sociais e culturais privados. Essa escola republicana construiu, até certo ponto, uma moral da razão, mas não construiu uma cidadania democrática (Dubet, 2011, p. 293).

Neste sentido,

A formação da cidadania não é apenas uma questão de princípios e de valores, ela inscreve na própria forma de escolarização, na maneira de operar as aprendizagens, num sistema de disciplina, num conjunto de regras. Ela procede, sobretudo, de uma forma escolar (Dubet, 2011, p. 293).

As relações entre educação e cidadania, interpretadas por François Dubet, não estão isentas de conflitualidades e dinâmicas de poder. A fabricação da unidade nacional, da autonomia do sujeito e as competências cidadãs explicitam importantes elementos da cidadania moderna, mas também revelam, em sua contraface, dispositivos institucionais de seleção (e consequente exclusão) de atores e coletividades em processos de formação escolar, memórias coletivas e patrimônios culturais. A cidadania, portanto, fez-se modelada por definições jurídico-normativas que lhe proporcionavam legitimidade e por "sínteses culturais estabelecidas em nome do nacionalismo" (Valle, 2000, p. 19) que lhe ofereciam uma história comum, mesmo que de modo artificial e contraditório ${ }^{2}$.

Notavelmente, a formação desta cidadania fundamentava-se na persistência dos programas massivos de escolarização inicial e na homogeneidade cultural dos relatos nacionalistas. Vejamos na seção a seguir como esta discussão tomou forma nas políticas de escolarização no Brasil e, a posteriori, como este modelo tem sofrido mutações nas paisagens culturais contemporâneas. 
Silva

\section{Escolarização no Brasil: políticas de unidade nacional}

A escolarização ingressou na agenda política brasileira no início da República. Desde 1870, fundamentada em teses liberais e democráticas moderadas, ainda não abolicionistas, a educação escolar ocupava um incipiente interesse para o estabelecimento de uma nova ordem social, sobretudo para "integrar e disciplinar, sobretudo a população imigrante para o trabalho na grande lavoura cafeeira” (Hilsdorf, 2011, p. 60). No contexto,

Fossem liberais, democráticas ou conservadoras, as forças políticas movimentam-se para controlar as instituições educativas e seus agentes e impor-lhes de modo definitivo a forma escolar como a mais adequada e eficaz para ministrar instrução e conformar a sociedade (Hilsdorf, 2011, p. 61).

O interesse em controlar a educação escolar estava na gênese das políticas estatais para o setor. Esse campo de disputas acabou por plasmar modelos escolares excludentes e injustos, parafraseando Anísio Teixeira (1977), num cenário histórico onde educação fez-se privilégio. No começo do século XX, diversas reformas estaduais e demais alterações nos marcos normativos foram esboçando a necessidade de modificar a estrutura e as finalidades do sistema de ensino. Professores e intelectuais posicionavam-se através de cartas públicas, documentos e manifestos a favor da democratização do acesso à educação escolar formal. O debate entre católicos e pioneiros, a partir da publicação do Manifesto dos Pioneiros da Educação Nova, em 1932, era expressivo destas tensões (Hilsdorf, 2011).

Dentre as diversas consequências desta conflitualidade histórica, interessa-nos compreender a emergência do nacionalismo como conteúdo para as nascentes políticas de escolarização brasileiras. A associação entre os pioneiros da educação e a pauta nacionalista derivou-se dos movimentos intelectuais dos anos de 1910 que demandaram a valorização da cultura brasileira em oposição à presença estrangeira no país. Entre 1915 e 1918, Olavo Bilac, por exemplo, empreendeu uma campanha de salvação nacional pela alfabetização e pelo serviço militar obrigatório, desencadeando a criação da Liga da Defesa Nacional, em 1916. O programa de ação desta liga era bastante amplo, envolvendo saúde, moral e trabalho, assim como a instrução cívica do povo (obediência às leis e respeito às tradições nacionais; celebração dos fatos nacionais; obrigatoriedade do ensino de língua, história e geografia pátrias, inclusive nas escolas estrangeiras) em detrimento da superação do ensino apenas alfabetizador (Hilsdorf, 2011). Embora atuante apenas até 1924, a Liga garantiu a inserção dos conteúdos nacionalistas na educação escolar, principalmente com o ensino de História do Brasil no primário.

Esse nacionalismo esteve igualmente presente nos movimentos culturais e estéticos na sociedade brasileira nas primeiras décadas do 
século XX. A Semana da Arte Moderna, em 1922, o Movimento Antropofágico e as primeiras experiências em políticas culturais, idealizadas por Mário de Andrade (Calabre, 2009; Silva, 2012), ilustram essa tendência. Neste contexto, em 1936, foi criado o Serviço do Patrimônio Histórico e Artístico Nacional (SPHAN), planejado pelo poeta modernista com o interesse no conhecimento, conservação e divulgação da cultura nacional. Tal projeto inclinou-se para um projeto de construção de uma cultura nacional oficial, de maneira que a consciência nacional seria materializada pela consciência patrimonial.

Além das políticas estatais para a escolarização e para a cultura, o nacionalismo ocupou centralidade no nascente mercado de bens simbólicos (Ortiz, 1988; 1985), cujo escopo das ações buscava a construção de uma identidade nacional. O início das transmissões radiofônicas no país, em 1922, marcou a identificação de uma Era do Rádio (Calabre, 2004). O rádio passou a ser instrumento de divulgação governamental e, portanto, ferramenta para produção da homogeneidade cultural e da unidade/identidade nacional.

O esforço de nacionalização representou o primeiro empenho da escolarização do Brasil, produzindo uma agenda pedagógica contraditória, uma vez que enfrentou apenas parcialmente as mazelas e os dilemas educacionais do país, mas fora eficiente no sentido de fabricar os sentidos de uma nação. A massificação da escolarização, a veiculação da ideologia e das tradições nacionais, o ensino cívico dos símbolos e dos hinos pátrios, a exaltação dos heróis nacionais, as datas comemorativas, o reconhecimento oficial do patrimônio da nação pelo SPHAN e sua conservação pela repetição de atividades escolares e a circulação das ideologias governamentais desencadearam uma nova condição histórica para a escolarização. Escolarizar contextualizava-se no bojo de um universo imaginário de significado, de um patrimônio coletivo e de uma memória comum. Embora estas lógicas estejam muito vinculadas à Era Vargas, toda experiência política posterior não negligenciou os mecanismos de elaboração da brasilidade.

Segundo Schwartzman, Bonemy e Costa (2000), é possível identificarmos três aspectos que reforçaram estas políticas de nacionalização. Primeiro, apontam para a necessidade de um conteúdo nacional a ser transmitido pela escolarização e outros processos formativos. Assim,

A natureza mais precisa deste 'conteúdo nacional' jamais ficou totalmente definida, mas é claro que ela não incorporaria aquela busca às raízes mais profundas da cultura brasileira que faziam parte da vertente andradiana do projeto modernista; ao contrário, tiveram preferência os aspectos do modernismo relacionados com o ufanismo verde e amarelo, a história mitificada dos heróis e das instituições nacionais e o culto às autoridades. Não faltava a esta noção de brasilidade, transmitida nas publicações 
oficiais e nos cursos de educação moral e cívica, a ênfase no catolicismo brasileiro, em detrimento de outras formas menos legítimas de religiosidade. Finalmente, a nacionalidade deveria firmar-se pelo uso adequado da língua portuguesa de forma uniforme e estável em todo o território nacional (Schwartzman; Bonemy; Costa, 2000, p. 157).

O segundo aspecto comentado pelos autores era a padronização. Havia, concomitante aos conteúdos nacionais, o ideal de homogeneidade e centralização na construção da escolarização no Brasil. Essa padronização notabilizou-se pela existência de uma universidade padrão, a busca por escolas-modelo, a elaboração de currículos mínimos obrigatórios e universais, a padronização dos materiais didáticos e a elaboração de sistemas federais de controle e fiscalização. Tal desejo materializava a representação de que, de seu escritório no Rio de Janeiro, o ministro pudesse "saber o que cada aluno estava estudando em cada escola do país em um momento dado” (Schwartzman; Bonemy; Costa, 2000, p. 157).

O terceiro aspecto era a "erradicação das minorias étnicas, linguísticas e culturais que se haviam constituído no Brasil nas últimas décadas, cuja assimilação se transformaria em uma questão de segurança nacional" (Schwartzman; Bonemy; Costa, 2000, p. 158). Nesta questão, a homogeneidade cultural, ou a fabricação de uma unidade nacional, tornava-se objeto de ação imediata, cujas providências legais demandavam fechamento de escolas de estrangeiros, nomeação de diretores e professores brasileiros e de construção de cidadania brasileira. O sentimento de nacionalidade, em especial no governo Vargas, era meticulosamente articulado entre ações fortes no enfrentamento das culturas estrangeiras e o fortalecimento de uma cultura cívica de pertencimentos e filiações sociais.

Educar para o patrimônio nacional tornava-se ação emblemática destes contornos da escolarização. O patrimônio, a unidade nacional e a brasilidade eram conteúdos incontornáveis para a escola pública brasileira. Tal como a escola republicana francesa ensinava a geografia e a história da nação (Dubet, 2011), a escola brasileira deveria ensinar $o$ Brasil, representação esta eivada por dispositivos de seleção da cultura, da história e da memória oficiais. Educar associava-se ao objetivo de conservação dos valores e do patrimônio próprios da unidade desejada para o país, mesmo que orientada por princípios elitizados e eurocêntricos. Embora não designada pela nomenclatura atual, educação patrimonial estava diluída nas escolas e em outras agências socializadoras do século XX.

Tais relações entre educação e patrimônio manifestavam-se nas principais cartas patrimoniais ${ }^{3}$ desde a Carta de Atenas, em 1931 (Cury, 2004). No Brasil, em específico, as referidas temáticas emergiram, sobretudo, nas contribuições de Rodrigo Melo Franco de Andrade, primeiro diretor do Serviço do Patrimônio Histórico e Artístico Nacional. 
O objetivo destas ações seria a produção de uma consciência preservacionista, matizada desde a gênese do SPHAN, a partir de uma responsabilidade compartilhada com outros órgãos educativos governamentais, principalmente pela escassez de recursos orçamentários destinados à cultura no Brasil.

Até a década de 1980, há uma relação de opacidade entre educação patrimonial e patrimonialização cultural. Ao mesmo tempo em que "processos de patrimonialização tornaram-se objetos de políticas públicas com agências voltadas para este fim" e "patrimonializar passou a significar um processo de escolha de determinados bens ou artefatos capazes de simbolizar ou de representar metaforicamente a ideia abstrata de nação e seus corolários, como a ideia de humanidade" (Abreu, 2015, p. 67), a educação patrimonial não existiu ou fez-se iniciativa secundária dirigida à produção da consciência patrimonial.

Em 1983, ocorreu no Museu Imperial, em Petrópolis, um seminário sobre o Uso Educacional de Museus e Monumentos. A proposição central informava sobre a atualização de trabalhos pedagógicos desenvolvidos na Inglaterra sob o nome de Heritage Education. Educação patrimonial é inserida, com mais regularidade, nas produções do Instituto do Patrimônio Histórico e Artístico Nacional (IPHAN), contribuindo para a publicação do Guia Básico de Educação Patrimonial, em 1999 (Horta; Grunberg; Monteiro, 1999). Tal publicação, embora educação patrimonial, na época, tivesse sido delineada a partir de sua dimensão estritamente metodológica, desencadeou um conjunto de novas experiências educativas em museus e instituições culturais, bem como engendrou novas relações entre as coletividades e seus patrimônios. No âmbito das intervenções governamentais, o documento não conduziu a reordenamentos substantivos em seu conteúdo político ou em sua posição institucional, visto na ausência da temática em políticas públicas no país. O documento, contudo, ofereceu uma (primeira) definição de educação patrimonial, entendida como "um instrumento de alfabetização cultural que possibilita ao indivíduo fazer a leitura do mundo que o rodeia, levando-o à compreensão do universo sociocultural e da trajetória histórico-temporal em que está inserido" (Horta; Grunberg; Monteiro, 1999, p. 6).

Ainda na década de 1980, foi desenvolvido o projeto Interação entre educação básica e os diferentes contextos culturais do país ${ }^{4}$, cujo princípio organizador era o levantamento de bens que constituiriam referências culturais, que pudessem ser "reconhecidos e valorizados pelo poder público como patrimônio cultural" (Londres, 2012, p. 19). Este projeto já apresentou uma concepção ampliada de patrimônio, influenciado por uma visão antropológica de cultura. A justificativa do projeto escrita por Aloísio Magalhães expõe esse primeiro deslocamento:

Num país com esse tamanho, com essa diversidade de composições étnicas, com a diversidade de climas, de 
situações geopolítica e geoeconômicas, não é possível se pensar numa forma centralizada de aprendizado. Dessa forma, centralizar significaria a morte do país, a morte da invenção, a morte da fantasia, a morte da liberdade (Magalhães, 1985, p. 67).

Historicamente, as políticas patrimoniais e de educação patrimonial estiveram assentadas em representações eurocêntricas de patrimônio e de memória, recursivamente demonstradas em tombamentos materiais derivados do universo cultural lusitano (colonial) e do Barroco, de maneira que sua ordem discursiva evidenciava uma retórica da perda (Gonçalves, 2011). A educação para a memória nacional foi enquadrada (Pollak, 1989) aos padrões de uma história oficial, invisibilizando e silenciando as culturas populares, as culturas tradicionais, as culturas indígenas e afro-brasileiras, dentre outras. Embora existam poucos registros deste projeto, a justificativa elaborada por Aloísio Magalhães parece indicar uma sensível ampliação do escopo reflexivo da política patrimonial.

Em todo caso, não é difícil observar, no âmbito das políticas brasileiras, a inexistência de uma política sistemática e duradoura para a educação patrimonial. Porém, como vimos nesta seção, a unidade nacional e a homogeneidade cultural compuseram uma agenda civilizatória aos programas de massificação escolar e, consequentemente, produziram sentidos às relações entre educação e patrimônio cultural no Brasil. A seguir, analisaremos os delineamentos contemporâneos destas relações.

\section{Educação, Educação Patrimonial e Diversidade Cultural}

A educação patrimonial ocupa ainda lugares incertos e difusos na construção das políticas brasileiras. Em alguma medida, desde a criação do SPHAN, na década de 1930, tal educação esteve associada à unidade nacional, à fabricação de um imaginário brasileiro ou mesmo à preservação de artefatos e representações tangíveis de patrimônio. Num contexto onde o patrimônio estava associado a suas dimensões materiais, de pedra e cal, a educação para o patrimônio ${ }^{5}$ esteve estritamente associada a cidades históricas que experimentaram processos de tombamento oficial, nas quais seu repertório pedagógico e cultural assumia contornos conservatórios. Conservar a ordem urbana, preservar os bens, resgatar um passado distante eram objetivos corriqueiros para iniciativas neste tipo de educação. Esta representação figurava uma definição estável, fixa e neutra de patrimônio, além de localizar sua discursividade em um passado desvinculado das mudanças socioculturais do tempo presente.

A década de 1970 trouxe-nos um novo elemento para situarmos a educação para o patrimônio no Brasil, qual seja: sua aproximação a planos e programas de desenvolvimento social ${ }^{6}$. A educação passa a vincu- 
lar-se a outros objetivos sociais (Silva, 2012), numa condição histórica onde a cultura passa a ser vista como recurso para projetos econômicos, políticos e sociais diferenciados (Yúdice, 2004). Nesta ordem social globalizada, patrimônio, cultura e educação passam a ser mediadores de expectativas de lucro, rentabilidade, desenvolvimento, assim como estas práticas são engajadas em novos regimes de organização. Como observa Zambrano (2000), a globalização reestabeleceu relações entre economia, direitos e culturas. Numa escala global, esses processos foram compondo novas agendas para as políticas da cultura e da educação, ao mesmo tempo em que, em outra direção, diversos atores, grupos e movimentos sociais passaram a intensificar suas reivindicações por direitos e por reconhecimento cultural (Silva, 2010). Reconhecimento cultural e redistribuição econômica vão ocupando centralidade nas lutas por justiça social (Fraser, 2001).

Como analisou Silva (2010), essa situação favoreceu a pluralização da agenda das políticas de escolarização no Brasil. Diversos programas e políticas setoriais passaram a considerar atores e coletivos antes ausentes da representação oficial da política, caso de negros, quilombolas, mulheres, indígenas, comunidades tradicionais, homossexuais, culturas populares, etc. Políticas para a cultura, a educação, a educação integral, os direitos humanos, a igualdade racial e de gênero vão comungando interesses de justiça social, cuja teleologia alcança a reconstrução das relações democráticas, constantes nos movimentos políticos brasileiros desde a luta por redemocratização e intensificados no texto da Constituição de 1988. Assim, respeito à diversidade cultural torna-se uma expressão-síntese de uma democratização cultural, consubstanciada pelo amadurecimento dos aspectos procedimentais da democracia. Embora, como observa Geertz (2001), a diversidade cultural também comporte usos, significações e intencionalidades absolutamente contraditórias.

Regina Abreu (2015), por sua vez, considera os processos de patrimonialização como um movimento próprio do mundo moderno ocidental, tendo em vista, por exemplo, a criação de agências nacionais e internacionais para o setor, a formação de agentes, a instituição de políticas públicas. Embora marcado por disputas e conflitos, a antropóloga sintetiza a trajetória da patrimonialização em três grandes momentos. Vejamos:

No primeiro, que vai do século XIX à primeira metade do século XX, os processos de patrimonialização fundamentavam-se na reconstrução do passado (história) ou na busca e valorização de uma arte nacional. No segundo, cujo marco fundamental foi a criação da Unesco nos anos 1940, uma nova e importante variável é absorvida pelos processos de patrimonialização: o conceito antropológico de cultura. É importante ressaltar que o projeto de criação desta agência internacional esteve ligado diretamente à busca da paz entre as nações após duas guerras 
mundiais. A noção de que os homens eram seres biologicamente semelhantes e que poderiam marcar suas diferenças pela cultura foi apropriada como um dos fundamentos da Unesco em a meta seria a troca e o intercâmbio entre as culturas para uma maior aproximação e, consequentemente, um maior entendimento entre os seres humanos (Abreu, 2015, p. 69).

Como vimos anteriormente, as ações patrimoniais brasileiras promovidas desde a década de 1980 foram influenciadas pela, assim designada, concepção antropológica de cultura. Esta definição, articuladas a outras condições sociais, favoreceu o advento de um terceiro momento:

O terceiro momento tem início no final dos anos 1980, particularmente com o lançamento pela Unesco da Recomendação de Salvaguarda das Culturas Tradicionais e Populares em 1989, quando as políticas preservacionistas passam a ser normatizadas por fóruns internacionais, com a predominância da Unesco, estimulando uma dinâmica globalizada de identificação, proteção, difusão e circulação de valores e signos patrimoniais. É neste período que se implanta o que estou chamando de tendência à 'patrimonialização das diferenças', em que a palavra de ordem, capitaneada pela Unesco, é que, 'num mundo com tendência crescente à homogeneização' protagonizada pelo capitalismo globalizado e neoliberal, é preciso preservar, ou seja: conceder especial atenção à noção de singularidade ou de especificidade local (Abreu, 2015, p. 69).

Esse fenômeno de patrimonialização das diferenças associa-se também a uma redefinição dos termos que circunscrevem os patrimônios, considerando-se, principalmente, uma ampliação nas definições do que pode ser interpretado como patrimônio, bem como a redução de potencial heurístico do binômio patrimônio material e imaterial. $\mathrm{O}$ referido processo inscreveu nos agentes interessados na pauta patrimonial, tanto quanto se observou a "entrada na cena pública de segmentos sociais antes invisíveis, oriundos das camadas populares e de sociedades tradicionais" (Abreu, 2015, p. 70). Com isso, tais processos deixaram de ser prerrogativa exclusiva de agentes autorizados pelo Estado, convertendo-se em um campo conflitivo de reivindicações por patrimonialização demandadas pelos próprios grupos sociais, condicionados por relações de força em distintos âmbitos da sociedade.

Contudo,

Podemos sintetizar assinalando que o campo do patrimônio na contemporaneidade constitui-se num campo assaz paradoxal: se, por um lado, abre-se uma comporta para um excesso de patrimonialização impulsionado pela 'política da patrimonialização das diferenças como forma de combate à homogeneização neoliberal', bem como pelas 
Educação Patrimonial e Políticas de Escolarização no Brasil

novas tecnologias e os modernos sistemas operacionais, por outro lado, fortalece-se o movimento inverso estimulando ações de distinção patrimonial, materializadas por meio dos selos de 'patrimônio mundial' ou de 'obra-prima do patrimônio oral e imaterial da humanidade' (Abreu, 2015, p. 71).

Essa discussão alcançou a educação patrimonial no começo do século XXI. Os sentidos mais clássicos de patrimônio são tensionados por novas deliberações jurídicas e normativas que ampliaram a ideia de patrimônio, incorporando suas dimensões intangíveis e também ambientais, genéticas ou naturais (Abreu, 2009). As culturas populares e tradicionais foram reconhecidas como patrimônio pelo Estado Brasileiro, sendo emblemáticos os registros ou tombamentos do ofício das paneleiras de goiabeiras, no Espírito Santo; a Arte Kusiwa e seus grafismos entre os povos indígenas Wajãpi, no Amapá; o Círio de Nossa Senhora de Nazaré, em Belém do Pará; o jongo na região sudeste do Brasil, dentre outros.

A chegada de Gilberto Gil ao Ministério da Cultura, em 2003, acelerou estes processos de reconhecimento político da diversidade cultural brasileira, assim como sua inserção em lógicas de desenvolvimento social a partir de circuitos de economia criativa (ou economia da cultura). Diversas experiências em educação e diversidade cultural ou em educação patrimonial foram potencializadas, a partir, por exemplo, da criação do Programa Cultura Viva que procurava consolidar experiências em políticas culturais em andamento no interior do país (Silva, 2012). Muitos Pontos de Cultura, principal iniciativa do programa, alocaram-se em instituições de ensino provocando pontos de intersecção entre as políticas de escolarização e as políticas culturais.

Entretanto, como estas dinâmicas socioculturais impactam a educação patrimonial? Como, na contemporaneidade, a educação patrimonial tem sido incorporada às políticas brasileiras de escolarização? Para responder a estas problematizações, apresentaremos uma análise documental de textos sobre a temática recentemente publicados pelo governo brasileiro.

\section{a) Interesse na institucionalização da política e a produção de uma agenda política}

O início deste século pareceu um contexto favorável para a composição de novas agendas políticas para diversos setores, uma vez que se identificou uma maior permeabilidade do Estado em relação às demandas oriundas da sociedade e de seus movimentos (Silva, 2010). Assim, diversos foram os fóruns, encontros, assembleias e conferências locais e nacionais reconhecidos como espaços legítimos para a interlocução entre os atores sociais e os segmentos/agentes estatais, desencadeando significativos processos de inserção de pautas nas lógicas de ação estatais. Obviamente, trata-se de um campo conflitivo e contesta- 
Silva

do, mediado por instâncias de poder e relações de força política, onde nem todas as demandas se institucionalizaram ou conseguiram formalizar procedimentos.

Entre 12 e 17 de setembro de 2005, ocorreu o I Encontro Nacional de Educação Patrimonial, em São Cristóvão, Sergipe. Para o IPHAN, este encontro representou um momento de síntese de seus processos de desenvolvimento de ações educativas, além da oportunidade de intensificar seus debates sobre educação patrimonial (Casco, 2013). O encontro explicitou um campo de tensionamentos entre os movimentos sociais, que reivindicavam o direito a escolher suas referências patrimoniais, e os agentes estatais (com interesses diversos) que historicamente demandam intervenções mais incisivas do Estado no setor. O relato de Ana Carmen Amorin Jara Casco ilustra esse tensionamento:

\begin{abstract}
Hoje lidamos, aparentemente, com a polaridade de duas situações: a iniciativa da sociedade, a partir de seus próprios pressupostos, de realizar ações, de cunho educativo, voltadas para a preservação do patrimônio e da memória de grupos sociais e em determinadas situações de risco, abandono, descaso e desvalorização; e a demanda por uma ação mais sistemática e agressiva do Estado que poderia se materializar, em princípio, através da cobrança pela elaboração e difusão de metodologias, normas e diretrizes que ajudassem a organizar esse campo (Casco, 2013, p. 2).
\end{abstract}

Esta percepção encaminhou, ao longo do encontro, para algumas conclusões. A primeira, destacada ainda por Casco (2013), é da impossibilidade de organizar o campo da educação patrimonial apenas com normas e metodologias pré-definidas, visibilizando-se o pressuposto de elaborar-se uma política nacional para o setor. Esta política, ainda em aberto no país, deveria conter as principais diretrizes da ação institucional, fomentar a participação dos atores engajados, objetivar o enfrentamento das desigualdades socioculturais e desenvolver uma proposta educativa que "desvende o rosto digno da diversidade brasileira" (Casco, 2013, p. 5).

O II Encontro Nacional de Educação Patrimonial ocorreu entre os dias 17 a 21 de julho de 2011, em Ouro Preto, Minas Gerais. Este encontro resultou na divulgação de um documento final intitulado Texto Base para uma Política Nacional no Âmbito da Educação Patrimonial, onde constam seus eixos temáticos, diretrizes e ações. O documento apresenta quatro eixos temáticos, dos quais se desdobram diretrizes e, destas, destacam-se ações. Embora trate de uma política em construção, o Texto Base explicita a importância da reorganização das institucionalidades políticas para a proposição de uma ação sistemática e intencional de longo prazo. O desenho organizativo desta política ainda situa-se numa condição incerta ou difusa, característica histórica da educação patrimonial, uma vez que almeja ainda sua consolidação nos dispositivos institucionais referentes à cultura, ao patrimônio e à escolarização. 
Educação Patrimonial e Políticas de Escolarização no Brasil

Enquanto ordem discursiva, o documento parece ter se orientado pela heterogeneidade das demandas democráticas (Dubet, 2007), enquanto sentido político-cultural para a escolarização, acompanhando toda uma tendência de patrimonialização das diferenças (Abreu, 2015) e de diversas reivindicações identitárias almejando inserção na agenda das políticas públicas.

\section{b) Educação e diversidade cultural: a educação patrimonial no Programa Mais Educação}

O Programa Mais Educação, instituído pela Portaria Interministerial No 17/2007 e pelo Decreto No 7.083/2010 (Brasil, 2010), é parte integrante do Plano de Desenvolvimento da Educação (PDE), no qual constitui uma plataforma de ação estratégica cujos eixos organizacionais são: a ampliação do tempo de permanência dos estudantes na escola pública (jornada escolar); a reorganização das dinâmicas curriculares das instituições de ensino diante das prerrogativas de ampliação do tempo e do espaço escolar; e a retomada da perspectiva pedagógica da educação integral.

Ao preocupar-se com problematizações sociais e educacionais, o Programa Mais Educação apropria-se de alguns movimentos próprios da cultura contemporânea e, de algum modo, articula-se com algumas respostas civilizacionais produzidas diante de cenários de desigualdades materiais e simbólicas, no Brasil (Silva, 2013). Esse debate tem sido tangenciado pela redefinição dos papéis da escola (ampliação de funções), igualmente pela necessidade de propostas pedagógicas qualificadas que articulem educar e proteger, ou mesmo uma reorganização no trabalho docente. Em seus aspectos operacionais, o programa visa à ampliação da jornada escolar, mediante a oferta de atividades complementares no contraturno escolar.

Recentemente, a educação patrimonial foi inserida no rol de temáticas (denominadas macrocampos) do programa. Em termos documentais, esta inserção é considerada uma mudança política significativa para as relações entre educação escolar e patrimônio cultural. Evidenciam-se importantes entrecruzamentos entre as políticas educacionais e as políticas culturais, numa situação onde a cultura parece ser usada (Yúdice, 2004) em duas escalas organizacionais. Numa escala exógena, parece que tal educação amplia-se para além de seu ordenamento político convencional. Educar passa a ser tarefa de todo o Estado, na busca de interlocuções com diversos setores da sociedade, com a cultura e com a memória regional, com os atores e movimentos sociais. Ao mesmo tempo, ações e temáticas próprias de outros segmentos estatais passam a circular pela escola pública, de modo que são inúmeros os projetos e agenciamentos culturais que se irradiam pelas instituições de ensino (Silva, 2012). 
Silva

Entretanto, os documentos sinalizam para mudanças mais substantivas em escalas organizacionais endógenas aos processos escolares. O documento público do Programa Mais Educação, o Texto Referência para o Debate Nacional, apresenta a seguinte constatação:

Toda escola está situada em uma comunidade com especificidades culturais, saberes, valores, práticas e crenças - o desafio é reconhecer a legitimidade das condições culturais da comunidade para estimular o diálogo constante com outras culturas. A educação é um dos ambientes da cultura marcada pela reconstrução de conhecimentos, tecnologias, saberes e práticas (Brasil, 2009, p. 32).

O Programa Mais Educação assume textualmente, enquanto diretriz político-cultural, uma perspectiva de respeito pedagógico à diversidade cultural. Nesse sentido, acompanha as discussões internacionais acerca do escopo de atuação da escola para comunidades educativas ou territórios educativos e visa a alcançar a cidade como espaço potencialmente pedagógico. O "enriquecimento das possibilidades formativas dos estudantes” (Moll, 2012), mediante ampliação do tempo, oportunizaria a centralidade às diversas manifestações e expressões culturais nessas outras experiências escolares. Em termos documentais, os saberes, as manifestações culturais (materiais e imateriais), as tradições e o artesanato, as produções estéticas e as musicalidades deveriam irradiar-se pelo currículo e pelas políticas de escolarização associadas ao programa.

Outra dimensão endógena esclarecedora destas ênfases da cultura nas políticas de escolarização pode ser observada quanto à educação patrimonial. A reorganização do macrocampo Cultura, Artes e Educação Patrimonial ${ }^{7}$ engendra a pertinência das memórias e do patrimônio cultural como conteúdo desta política, considerando a promoção e o respeito às diferenças culturais e às múltiplas produções estéticas como diretriz. Ao valorizar as expressões culturais, estabelece parâmetros de ação pedagógica orientados pela ruptura com os primados monoculturais derivados ainda das mudanças sociais vividas na transição ao século XIX (Silva, 2010). De outra parte, revela a influência da Unesco na agenda deste programa, tal como ocorre nas demais ações patrimoniais em nosso país.

A ementa do referido macrocampo indica seu principal deslocamento:

Incentivo à produção artística e cultural, individual e coletiva dos estudantes como possibilidade de reconhecimento e recriação estética de si e do mundo, bem como da valorização às questões do patrimônio material e imaterial, produzido historicamente pela humanidade, no sentido de garantir processos de pertencimento ao local e à sua história (Brasil, 2012, p. 17).

Educação \& Realidade, Porto Alegre, v. 41, n. 2, p. 467-489, abr./jun. 2016. 
As atividades propostas nesta área de planejamento do Programa Mais Educação evidenciam o interesse articulado entre a educação patrimonial e os múltiplos processos de patrimonialização cultural vigentes no Brasil. Assim, a proposição de oficinas como Artesanato Popular, Capoeira, Educação Patrimonial, Hip Hop ou Práticas Circenses seriam emblemáticas dos objetivos consequentes da ementa acima. Na composição descritiva das atividades específicas à educação patrimonial, visibiliza-se, com efeito, o respeito às diferenças e à diversidade expressiva da cultura. Seu objetivo explicita tal sentido:

Promover ações educativas para a identificação de referências culturais e fortalecimento dos vínculos das comunidades com seu patrimônio cultural e natural, com a perspectiva de ampliar o entendimento sobre a diversidade cultural (Brasil, 2012, p. 18).

A inserção da educação patrimonial neste programa prevê a ampliação dos âmbitos das aprendizagens dos atores, conferindo às culturas e às cidades lugar de conteúdo e de territorialidade para as experiências escolares. Assim, dá-se ênfase à investigação das práticas e referências culturais presentes na escola e em seu entorno, prospectando, ao menos no marco documental, interesse investigativo pelas culturas brasileiras, no plural. A pesquisa de referências culturais é uma metodologia desenvolvida pelo IPHAN como instrumento para "subsidiar as ações de registro e realizar um recenseamento mais amplo das manifestações culturais do país” (Abreu, 2015, p. 80). De certo modo, tal princípio metodológico parece ampliar os modos como a educação patrimonial foi vista historicamente no Brasil e adensar a hipótese da atual patrimonialização das diferenças, uma vez que "é perceptível o quanto estes processos deixaram de contemplar quase que exclusivamente reconstruções do passado para focalizarem manifestações culturais vivas e pulsantes como festas, rituais, saberes, conhecimentos tradicionais" (Abreu, 2015, p. 72).

Essas mudanças, de modo amplo, têm acompanhado o deslocamento da educação patrimonial para o centro de importantes produções acadêmicas, em muitos casos de maneira interdisciplinar. No âmbito das questões educativas, destacam-se as elaborações de Sandra Pelegrini (2009) e Barroso (2010) sobre as relações entre educação patrimonial e ensino de História; assim como os estudos de André Luís Ramos Soares sobre educação patrimonial em museus (Soares, 2009), as leituras de Carmen Perez (2009) sobre a alfabetização patrimonial e o trabalho de Gilmar Rocha, Adriana Russi e Johnny Alvarez (2013) sobre a concepção de uma etnoeducação patrimonial. Ainda em perspectivas socioantropológicas, destacam-se as elaborações de Néstor Garcia Canclini (2007), Mónica Rotman (2010) e Regina Abreu, Mário de Souza Chagas e Myriam Sepúlveda dos Santos (2007). O que parece comum a estes estudos e análises empíricas é uma preocupação contemporânea 
em recompor as definições e usos de educação patrimonial em contextos de pluralização identitária e de afirmação de diferentes processos de reconhecimento cultural, em evidente contraponto com as suas primeiras concepções que se assentavam na configuração de uma identidade/unidade nacional ${ }^{8}$.

\section{Considerações Finais}

No presente artigo, procuramos reconstruir a trajetória na educação patrimonial nas políticas brasileiras de escolarização. A construção da análise, que intercalou estudos bibliográficos e análise documental, ofereceu-nos elementos contrastivos que reforçaram binômios consagrados na análise social, a saber: unidade/diversidade e homogeneidade/heterogeneidade. Parece-nos que tais argumentos apresentam-se oportunos para a compreensão dos deslocamentos de sentido sofridos pela educação patrimonial em diferentes conjunturas históricas.

Na contemporaneidade, a diversidade cultural, em sentido politicamente afirmativo, tem desencadeado mudanças políticas que alcançam o conteúdo e as formas de elaboração de propostas educacionais em regimes democráticos. O reconhecimento da multiplicidade de atores, culturas e identidades culturais oferecem subsídios para a elaboração de programas democráticos para as políticas, ao passo em que dinamizam processos e metodologias de intervenção pautadas pela justiça social e pelo enfrentamento das desigualdades socioculturais. Contudo, a presença da educação patrimonial no contexto mais amplo das políticas para a patrimonialização das culturas no Brasil ainda é bastante periférica, bem como em políticas para a escolarização, tendo em vista uma miríade de interesses econômicos e políticos em disputa no que tange à definição de patrimônio e à efetuação de seus projetos na educação escolar.

Nesse cenário social, onde as objetivações econômicas ainda têm tangenciado os principais debates pedagógicos, mas, ao mesmo tempo, verificamos a emergência de discussões sobre a patrimonialização das diferenças (Abreu, 2015) e uma tendência mais inclusiva frente à heterogeneidade das demandas democráticas (Dubet, 2007), a educação patrimonial se impõe como uma problemática fundamental aos estudos contemporâneos em Sociologia da Educação.

Recebido em 22 de abril de 2015 Aprovado em 19 de março de 2016

\section{Notas}

1 Martín-Barbero (2009) justifica a necessidade de historicizar os processos e dinâmicas nas análises sociais, não no sentido de elaborar uma história das concepções e dos termos, mas de considerar e compreender as posições constituídas em lutas, conflitos e movimentos sociais.

Educação \& Realidade, Porto Alegre, v. 41, n. 2, p. 467-489, abr./jun. 2016. 
2 Esse argumento acompanha duas importantes elaborações sobre a produção cultural do nacionalismo europeu, a saber: Comunidades Imaginadas, de Benedict Anderson (2008), e A Invenção das Tradições, de Eric Hobsbawn e Terence Ranger (2012).

3 Cartas patrimoniais são documentos de referência sobre a preservação de bens culturais. A Carta de Atenas, de relevância internacional, publicada em reunião da Sociedade das Nações em 1931, é um dos primeiros documentos públicos a fazer circular recomendações acerca das relações entre os museus e a sociedade.

4 Projeto idealizado por Aloísio Magalhães e desenvolvido através de parceria entre o Ministério da Educação e o IPHAN.

5 Ao longo dessa análise, procuramos evidenciar uma distinção terminológica entre educação patrimonial e educação para o patrimônio. Mesmo que tenhamos indicado que, desde a década de 1930, o interesse educativo estivesse relativamente presente nas intervenções governamentais para o patrimônio no Brasil, o uso do termo educação patrimonial consolida-se apenas a partir da década de 1980.

6 O Projeto Cidades Históricas (PCH) implementado na década de 1970, por exemplo, explicitava intencionalidades de desenvolvimento cultural, prevendo uma articulação entre educação, patrimônio e desenvolvimento econômico (Silva, 2012).

7 Nos primeiros cinco anos do Programa, o macrocampo que organizava as ações pedagógicas atinentes à cultura chamava-se Cultura e Artes.

8 O que não significa que os autores deixem de considerar analiticamente suas relações de hierarquia e poder, seus conflitos, configurações e alteridades (Rotman, 2010).

\section{Referências}

ABREU, Regina. A emergência do patrimônio genético e a nova configuração do campo do patrimônio. In: ABREU, Regina; CHAGAS, Mario (Org.). Memória e Patrimônio: ensaios contemporâneos. 2. ed. Rio de Janeiro: Lamparina, 2009. P. 34-48.

ABREU, Regina. Patrimonialização das diferenças e os novos sujeitos de direito coletivo no Brasil. In: TARDY, Cécile; DODEBEI, Vera (Org.). Memória e Novos Patrimônios. Marseille: Open Edition Press, 2015. P. 67-93

ABREU, Regina; CHAGAS, Mario; SANTOS, Myriam (Org.). Museus, Coleções e Patrimônios: narrativas polifônicas. Rio de Janeiro: Garamond, 2007.

ANDERSON, Benedict. Comunidades Imaginadas: reflexões sobre a origem e a difusão do nacionalismo. São Paulo: Companhia das Letras, 2008.

BARROSO, Vera. Educação patrimonial e ensino de história: registros, vivências e proposições. In: BARROSO, Vera (Org.). Ensino de História: desafios contemporâneos. Porto Alegre: EST, 2010. P. 15-37.

BAUMAN, Zygmunt. Comunidade: a busca por segurança no mundo atual. Rio de Janeiro: Zahar, 2003.

BRASIL. Decreto n. 7.083, 27 de janeiro de 2010. Dispõe sobre o Programa Mais Educação. Diário Oficial [da República Federativa do Brasil], Brasília, DF, 27

486 Educação \& Realidade, Porto Alegre, v. 41, n. 2, p. 467-489, abr./jun. 2016. 
Silva

jan. 2010. P. 2. (Edição Extra). Disponível em: <http://www.planalto.gov.br/ccivil_03/_ato2007-2010/2010/decreto/d7083.htm>. Acesso em: 20 ago. 2013.

BRASIL. Ministério da Educação. Educação Integral: texto referência para o debate nacional. Brasília: Secretaria de Educação Continuada, Alfabetização e Diversidade, 2009.

BRASIL. Ministério da Educação. Manual Operacional de Educação Integral. Brasília: Secretaria de Educação Básica; Diretoria de Currículos e Educação Integral, 2012.

CALABRE, Lia. A Era do Rádio. Rio de Janeiro: Zahar, 2004.

CALABRE, Lia. Políticas Culturais no Brasil: dos anos 1930 ao século XX. Rio de Janeiro: FGV, 2009.

CANCLINI, Néstor Garcia. A Globalização Imaginada. São Paulo: Iluminuras, 2007.

CASCO, Ana. Sociedade e Educação Patrimonial. 2013. Disponível em: <http:// portal.iphan.gov.br/uploads/ckfinder/arquivos/sociedade_e_educacao_patrimonial(1).pdf >. Acesso em: 20 ago. 2013.

CURY, Isabelle (Org.). Cartas Patrimoniais. 3. ed. Rio de Janeiro: IPHAN, 2004.

DELGADO, Ana. Configurações do campo do patrimônio no Brasil. In: BARRETO, Euder (Org.). Patrimônio Cultural e Educação: artigos e resultados. Goiânia: Ed. UFG, 2008. P. 97-115.

DOMINGUES, José Maurício. Do Ocidente à Modernidade: intelectuais e mudança social. Rio de Janeiro: Civilização Brasileira, 2003.

DUBET, François. El declive y las mutaciones de la institución. Revista de Antropología Social, Madrid, n. 16, p. 39-66, 2007.

DUBET, François. Mutações cruzadas: a cidadania e a escola. Revista Brasileira de Educação, Rio de Janeiro, v. 16, n. 47, p. 289-305, 2011.

DURKHEIM, Emile. O ensino da moral na escola primária. Novos Estudos, n. 78, p. 59-75, 2007.

ELIAS, Norbert. O Processo Civilizador - v. 1: uma história dos costumes. 2. ed. Rio de Janeiro: Zahar, 2011.

FRASER, Nancy. Da redistribuição ao reconhecimento? Dilemas da justiça na era pós-socialista. In: SOUZA, Jessé (Org.). Democracia Hoje. Brasília: Ed. UNB, 2001. P. 245-282.

GEERTZ, Clifford. Nova Luz sobre a Antropologia. Rio de Janeiro: Zahar, 2001.

GIDDENS, Anthony. As Consequências da Modernidade. São Paulo: Editora UNESP, 1991.

GOHN, Maria da Glória. O Protagonismo da Sociedade Civil: movimentos sociais, ONGs e redes solidárias. 2. ed. São Paulo: Cortez, 2008.

GONÇALVES, José Reginaldo. Culturas populares: patrimônio e autenticidade. In: BOTELHO, André; SCHWARCZ, Lilia Moritz (Org.). Agenda Brasileira: temas de uma sociedade em mudança. São Paulo: Companhia das Letras, 2011. P. 134141.

HILSDORF, Maria Lúcia. História da Educação Brasileira: leituras. São Paulo: Cengage Learning, 2011.

HOBSBAWN, Eric; RANGER, Terence. A Invenção das Tradições. 2. ed. São Paulo: Paz e Terra, 2012.

Educação \& Realidade, Porto Alegre, v. 41, n. 2, p. 467-489, abr./jun. 2016. 
HORTA, Maria de Lourdes; GRUNBERG, Evelina; MONTEIRO, Adriana. Guia Básico de Educação Patrimonial. Brasília: IPHAN, 1999.

LONDRES, Cecilia. O patrimônio cultural na formação das novas gerações: algumas considerações. In: TOLENTINO, Atila (Org.). Educação Patrimonial: reflexões e práticas. João Pessoa: Superintendência do Iphan na Paraíba, 2012. P. 14-21.

LYON, David. Pós-modernidade. São Paulo: Paulus, 1998.

MAGALHÃES, Aloísio. E triunfo? - A questão dos bens culturais no Brasil. Rio de Janeiro: Nova Fronteira, 1985.

MANZINI, Maria. O que é Cidadania. 4. ed. São Paulo: Brasiliense, 2010.

MARSHALL, Thomas. Cidadania, Classe Social e Status. Rio de Janeiro: Zahar Editores, 1967.

MARTÍN-BARBERO, Jesús. Dos Meios às Mediações: comunicação, cultura e hegemonia. 6. ed. Rio de Janeiro: Editora UFRJ, 2009.

MOLL, Jaqueline. A agenda da educação integral: compromissos para consolidação da política pública. In: MOL, Jaqueline (Org.). Caminhos da Educação Integral no Brasil: direito a outros tempos e espaços educativos. Porto Alegre: Artmed, 2012. P. 129-146.

ORTIZ, Renato. Cultura Brasileira e Identidade Nacional. São Paulo: Brasiliense, 1985.

ORTIZ, Renato. A Moderna Tradição Brasileira - Cultura Brasileira e Indústria Cultural. São Paulo: Brasiliense, 1988.

PELEGRINI, Sandra. Apontamentos para uma experiência de articulação entre ensino de história e a educação patrimonial no Paraná. Cadernos do CEOM, Chapecó, n. 30, p. 375-396, 2009.

PEREZ, Carmen Lúcia. Rodas de memórias e saberes: uma prática de formação. In: PEREZ, Carmen Lúcia; TAVARES, Maria Tereza; ARAUJO, Mairce. Memórias e Patrimônios: experiências em formação de professores. Rio de Janeiro: Eduerj, 2009. P. 253-267.

POLLAK, Michael. Memória, esquecimento, silêncio. Estudos Históricos, Rio de Janeiro, v. 2, n. 3, p. 3-15, 1989.

ROCHA, Gilmar; RUSSI, Adriana; ALVAREZ, Johnny. Etnoeducação patrimonial: reflexões antropológicas em torno de uma experiência de formação de professores. Pro-posições, Campinas, v. 24, n. 2, p. 55-67, 2013.

ROTMAN, Mónica. El campo patrimonial: procesos de configuración y problematización de alteridades. Revista Memória em Rede, Pelotas, v. 1, n. 1, p. 22-42, 2010. SCHWARTZMAN, Simon; BONEMY, Helena; COSTA, Vanda. Tempos de Capanema. São Paulo: Paz e Terra/FGV, 2000.

SILVA, Rodrigo Manoel Dias da. Os direitos culturais e a política educacional brasileira na contemporaneidade. Revista Brasileira de Política e Administração da Educação, Porto Alegre, v. 26, n. 1, p. 123-136, 2010.

SILVA, Rodrigo Manoel Dias da. Políticas Culturais em Cidades Turísticas Brasileiras: um estudo sobre as técnicas de vida contemporâneas. 2012. Tese (Doutorado em Ciências Sociais) - Programa de Pós-Graduação em Ciências Sociais. Universidade do Vale do Rio dos Sinos, São Leopoldo, 2012.

SILVA, Rodrigo Manoel Dias da. Programa Mais Educação: um novo lugar para a cultura nos projetos de formação escolar? Saberes \& Fazeres Educativos, Getúlio Vargas, v. 12, n. 1, p. 25-30, 2013.

488 Educação \& Realidade, Porto Alegre, v. 41, n. 2, p. 467-489, abr./jun. 2016. 
SOARES, Andre Luiz. Dr. Jeckyl and Mister Hide ou que educação patrimonial queremos nos museus? Cadernos do CEOM, Chapecó, n. 31, p. 283- 295, 2009.

TEIXEIRA, Anísio. Educação Não é Privilégio. 4. ed. São Paulo: Editora Nacional, 1977.

TIRAMONTI, Guillermina. La escuela en la encrucijada del cambio epocal. Educação \& Sociedade, Campinas, v. 26, n. 92, p. 889-910, 2005.

VALLE, Lilian. Cidadania e Escola Pública. In: VALLE, Lilian (Org.). O Mesmo e o Outro da Cidadania. Rio de Janeiro: DP\&A, 2000. P. 13-32.

YÚDICE, George. A Conveniência da Cultura: usos da cultura na era global. Belo Horizonte: Editora UFMG, 2004.

ZAMBRANO, Carlos. Diversidad cultural ampliada y educación para la diversidad. Nueva Sociedad, Buenos Aires, n. 165, p. 148-159, 2000.

Rodrigo Manoel Dias da Silva é Professor do Programa de Pós-Graduação em Educação da Universidade do Vale do Rio dos Sinos. Mestre e Doutor em Ciências Sociais pela Universidade do Vale do Rio dos Sinos.

E-mail: rodrigoddsilva@hotmail.com 